\title{
IBN ḤAWṬ ALLĀH (M. 612/1215) Y DOS MUJERES DE SEVILLA ${ }^{1}$
}

\section{IBN ḤAWṬ ALLĀH (M. 612/1215) AND TWO WOMEN FROM SEVILLA}

\author{
MANUELA MARÍN \\ ILC, CSIC
}

\begin{abstract}
Abū Muḥammad 'Abd Allāh b. Sulaymān Ibn Ḥawt Allāh y otros miembros de su familia han venido siendo objeto de atención desde que, en 1927, Asín Palacios se ocupó del «célebre teólogo granadino Benhautalá», al que incluyó en su catálogo de «discípulos mediatos» de Ibn Hazm ${ }^{2}$. Años después J. M. Fórneas dedicó un detallado estudio a este personaje, así como a otros miembros de su familia: su padre, Sulaymān b. Dā'ūd b. 'Abd al-Raḥmān b. Sulaymān b. 'Umar b. Hawṭ Allāh al-Anșārī al-Tuwayzī (m. 567/1171), su hermano Abū Sulaymān Dā'ūd (m. 621/1224), su hijo Aḥmad y su sobrino Muḥam$\mathrm{mad}^{3}$. La mayor parte de ese estudio, sin embargo, estaba dedicada al análisis y posibles orígenes del nombre familiar, tema sobre el que volvió poco después J. Oliver Asín ${ }^{4}$, para manifestar su desacuerdo con alguna de las propuestas de Fórneas. Al mismo tiempo, planteaba Oliver Asín un posible origen de la familia en un caserío llamado Faudella, al norte de Lérida, para deducir de ello que los Ḥawt Allāh

${ }^{1}$ Este trabajo se incluye en el proyecto de investigación "Movilidad geográfica y social de la población musulmana de la Península Ibérica (s. XI-XIII)", HUM2006-08644/FILO.

2 Asín Palacios, M., Abenházam de Córdoba y su historia crítica de las ideas religiosas, Madrid, 1927, I, 307.

${ }^{3}$ Fórneas, J. M., "Sobre los Banū Hawt Allāh (=Hawtella) y algunos fenómenos fonéticos del árabe levantino", Al-Andalus, XXXII (1967), 445-457. Fórneas hizo un uso exhaustivo, como era habitual en sus trabajos, de toda la documentación biográfica y biobibliográfica a su alcance, por lo que muy poco más se ha podido añadir después a sus referencias (cf. M. Penelas y J. Zanón, "Nómina de ulemas andalusíes de época almohade", M. Fierro y M. L. Ávila (eds.), Biografias almohades, I (EOBA, IX), Madrid-Granada, $1999,11-222$, n. $^{\circ} 213,577,630$ y 910$)$.

4 "En torno a los Banū Hawt Allāh", Al-Andalus, XXXIII (1968), 221-229. Los datos sobre los Banū Hawt Alläh, en este artículo, proceden del publicado por Fórneas y del texto de Asín Palacios citado más arriba.
\end{abstract}


fueron «primero, catalanes; luego, valencianos; y al fin, malagueños» ${ }^{5}$.

Las relaciones de Ibn Hawt Allāh con Averroes, de quien había sido discípulo, pero hacia el que manifestó más tarde una abierta oposición, se han dado también a conocer no hace mucho ${ }^{6}$. La aportación de mayor entidad, no obstante, para el conocimiento de la vida de Ibn Hawt Allāh es la larga biografía que le ha dedicado C. Adang dentro de su estudio sobre los zāhiríes de época almohade ${ }^{7}$, biografía que aporta una cuidadosa lectura de las fuentes biográficas que, en no escaso número, se ocuparon de Ibn Hawt Allāh, y en la que se sitúa adecuadamente a este personaje dentro del contexto intelectual de su época.

Todos estos estudios han agotado, prácticamente, las posibilidades de explotación de los documentos biográficos relativos a Ibn Hawt Allāh, por lo cual no cabría volver a ocuparse de él de no surgir nuevas informaciones que puedan añadirse a lo contenido en la literatura biobibliográfica ya conocida.

No hace mucho tiempo, consultando la colección de consultas jurídicas reunida por el tunecino al-Burzulī (m. 841/1438), tropecé con un texto en el que se daba ese caso, es decir, se trataba un episodio de la vida de Ibn Hawt Allāh que no aparecía recogido en ninguna de sus biografías. El texto en sí, por otra parte, contenía otros datos de interés no desdeñable para la historia social de la Sevilla almohade, por lo que he creído conveniente darlo a conocer. Ésta es su traducción:

Estábamos departiendo un día en presencia de un alfaquí que había ejercido como juez en al-Andalus e Ifrīqiya, el cual dijo:

— ¿Sabéis cuál fue la razón de la llegada de Abū Muhammad Ibn Hawt Allāh, el tradicionista, a vuestro país?

Le pedimos que nos informara sobre ello y nos contó lo siguiente:

Siendo Abū Muḥammad qā ḍ̄ de Sevilla, dos mujeres de familia noble, entre las que había enemistad, fueron [un día] al baño. Una de ellas ordenó a sus sirvientas que colocaran sus ropas en medio de las de la otra y así lo hicieron. Cuando después salió, pidió sus ropas, pero no se encontraron. La mujer dijo entonces a la dueña del baño: «He visto a Fulana en el baño; ella es la única que ha podido coger mis ropas». La encargada lo negó, diciendo: «¿Ella, que es de tan buena

5 Ibidem, 229.

${ }^{6}$ Puig, J., "Materials on Averroes's circle", JNES, 51 (1992), 241-260, esp. 253.

7 "Zāhiris of Almohad times", M. L. Ávila y M. Fierro (eds.), Biografías almohades, II (EOBA, X), Madrid-Granada, 2000, 413-479, esp. 433-443.

Al-Qanțara (AQ) XXIX 1, enero-junio 2008, pp. 209-219 ISSN 0211-3589 
casa, va a hacer una cosa así? Yo te compensaré por los vestidos». [La mujer] insistió en que se inspeccionaran las ropas y pidió que las trajeran; las mujeres testificaron en contra de la otra. Se elevó el asunto a Ibn Hawṭ Allāh, que cogió a la mujer y ordenó que fuera encarcelada o, según otros, azotada. Después [alguien] intercedió por ella ${ }^{8}$ y la dejó ir.

El hermano de esta mujer se levantó en la mezquita aljama de Sevilla y emplazó a Ibn Hawt Allāh ante el emir de los creyentes, al-Nāșir, que estaba entonces asediando al-Mahdīya. Ibn Hawt Allāh abandonó el país y le siguió, hasta que [ambos] llegaron ante al-Nāșir. El hombre le sometió su caso, que tanto él como los alfaquíes consideraron un asunto muy grave.

Dijo el emir de los creyentes: «que se conceda a esta mujer el derecho al talión». Esto se hizo muy penoso para los alfaquíes que estaban con él [Ibn Hawt Allāh] y no dejaron de congraciarse con su oponente [el hermano] hasta que le concedió el perdón, y eso que llevaba consigo un poder de su hermana exigiendo ese castigo ${ }^{9}$.

El interés de este texto es múltiple, como ya se ha dicho. En primer lugar, da alguna precisión cronológica sobre la vida de Ibn Ḥawt Allāh. Por la literatura biográfica que le concierne se sabe que fue juez en Córdoba, Mallorca, Sevilla, Murcia, Salé y Ceuta aunque, como señala C. Adang, esas fuentes no hacen constar las fechas en las que ejerció su cargo en estas ciudades ${ }^{10}$. Gracias a una fuente cronística se puede datar, por otra parte, el año (607/1210-11) en que Ibn Ḥawt Allāh fue destituido como juez de Murcia y nombrado para el mismo cargo en Córdoba ${ }^{11}$; ahora, gracias al texto recogido por al-Burzulī, se puede fechar el período en que ejerció la judicatura en Sevilla, ya que en ese momento el califa almohade al-Nāșir estaba asediando al-Mahdìya, que acabó tomando el 27 de ŷumādà I de 602/9 de enero de $1206^{12}$. Ese año, Ibn Hawt Allāh contaba 52 de edad.

${ }^{8}$ En el texto árabe, takallama fî-hā. El sentido con el que se ha traducido esta expresión no suele encontrarse en los diccionarios (o si lo hace, tiene otro régimen preposicional; cf. WKAS, I, 331, 1. 30). Pero se halla claramente documentado en Abū l-Faraŷ al-Ișfahānī, Kitāb al-Agānī, 'A. al-N. Nāṣif (ed.), vol. XX, El Cairo, 1972, 397, donde takallama $f \grave{\imath}$ aparece como sinónimo de šafa 'a (debo esta referencia a L. Molina).

9 Al-Burzulī, Ŷāmi masā'il al-aḥkām li-mā nazala min al-qaḍāyā bi-l-muftīn wa-l-hukkām, M. al-H. al-Hīla (ed.), Beirut, 2002, VI, 378-379.

${ }_{10}$ Sí se sabe que pasó un período de su vida como preceptor de los hijos del califa almohade al-Manșūr y que fue después cuando fue nombrado juez de Mallorca (Adang, C., "Zāhiris of Almohad times", 436).

11 Ibn 'Id̄ārī, Al-Bayān al-mugrib. Qism al-muwahhịidīn, M. I. al-Kattānī et alii (eds.), Casablanca, 1985, 256.

${ }_{12}$ Huici Miranda, A., Historia política del imperio almohade, II, Tetuán, 1957, 405-406; Lévi-Provençal, E., "Al-Nāṣir", EI ${ }^{2}$, s.v.

Al-Qanțara (AQ) XXIX 1, enero-junio 2008, pp. 209-219 ISSN 0211-3589 
Pero por supuesto, más allá de esta precisión cronológica, lo más relevante de este texto para la biografía de Ibn Hawt Allāh es el relato de su viaje a Ifrīqiya y las razones que le impulsaron o, más bien, le obligaron a realizarlo. Si se da crédito al informador de al-Burzulī (que no se identifica en ningún momento), un asunto relativamente trivial en origen, que se llevó a su juzgado, fue el detonante de una acción judicial que llegó a tomar proporciones desmesuradas.

El texto dice claramente que las dos mujeres que originaron todo el asunto pertenecían a familias nobles de la ciudad de Sevilla (min a 'yāni-hā), pero no explica la causa de la enemistad que había entre ellas, ni si procedía de una cuestión personal o de una rivalidad entre sus respectivas familias. En otro lugar me he referido al antagonismo que enfrentaba, en Sevilla, a las poderosas familias de los Banū 1-Ŷadd, los Banū 'Aẓima y los Banū Zuhr; en algún caso se afirma explícitamente que los enfrentamientos entre ellas estaban motivados por su lucha por el poder político y económico en la ciudad, todo ello durante el califato de los inmediatos predecesores de al-Nāșir ${ }^{13}$. Pudo darse una situación muy semejante entre las familias a las que pertenecían estas dos mujeres, una de las cuales no desperdició la circunstancia que se le ofrecía para perjudicar a la otra.

El alfaquí que relata la historia, evidentemente andalusí, sitúa su inicio en un baño público de Sevilla, al que habían acudido ambas mujeres, acompañadas de sus sirvientas ${ }^{14}$. Como es sabido, una corriente de opinión muy difundida entre los juristas musulmanes condena tajantemente la presencia de mujeres en los baños, a los que sólo les debería estar permitido acudir en caso de enfermedad o tras el parto ${ }^{15}$. El mismo al-Burzulī, en otro lugar de su compilación ${ }^{16}$, repro-

13 Marín, M., “Abū Bakr Ibn al-Ŷadd y su familia”, M. Fierro y M. L. Ávila (eds.), Biografias almohades, I (EOBA, IX), Madrid-Granada, 1999, 223-259, esp. 252-253.

14 Sobre los baños públicos de Sevilla, v. Torres Balbás, L., "Notas sobre Sevilla en la época musulmana", Al-Andalus, X (1945), 177-196 (esp. 179-186); Valor Piechotta, M., "Los baños en la Sevilla islámica", Arqueología Medieval, 3 (1993), 161-169 y Amores Carredano, F. de y Vera Reina, M., "El baño de la reina mora", Sevilla almohade, M. Valor Piechotta y A. Tahiri (coords.), Sevilla, 1999, 155-159.

${ }_{15}$ Véanse esta y otras opiniones semejantes en C. de la Puente, "Juridical Sources for the Study of Women: Limitations of the Female's Capacity to Act According to Māliki Law", M. Marín y R. Deguilhem (eds.), Writing the Feminine: Women in Arab Sources, Londres, 2002, 95-110, esp. 102-105 y "Mujeres andalusíes y baños públicos", Baños árabes en Toledo, Toledo, 2006, 49-57.

16 Ŷāmi ' masā'il al-ạ̣kām, III, 661-662.

Al-Qanțara (AQ) XXIX 1, enero-junio 2008, pp. 209-219 ISSN 0211-3589 
duce esta opinión y otras semejantes, entre las que puede destacarse la sentencia pronunciada por 'Abd al-Malik b. Habīb ${ }^{17}$ cuando se le pregunta si debe la autoridad (al-sultān) prohibir la entrada de las mujeres en los baños, a lo que responde lo siguiente:

Debe hacerlo y de la forma más enérgica. Yo no he visto en Medina que las mujeres entrasen en los baños. Soy de la opinión que debe prohibírseles esto enérgicamente e imponérselo, así como se debe instruir al dueño del baño para que ninguna mujer entre en él. El baño es para los hombres, y no debe hacerse si no es con pudor y recato. Ésta era la opinión de Aṣbag ${ }^{18}$.

La pervivencia, a lo largo de los siglos, de esta posición contraria a la presencia de mujeres en los baños no es nada sorprendente; coincide con otras limitaciones a la aparición de mujeres en lugares públicos, expresadas con igual entusiasmo por moralistas, censores de costumbres, teólogos y expertos jurisperitos ${ }^{19}$. Otra cosa, por supuesto, eran las prácticas sociales, que no siempre se adecuaban a esas normas teóricas ${ }^{20}$. En el caso de la prohibición a las mujeres de ir a los baños, la constancia con que se repite es ya un indicio de su limitada aplicación. Por otra parte, no faltan textos en los que se alude sin condena alguna a la presencia de mujeres en los baños; éste reproducido por al-Burzulī a propósito de Ibn Ḥawt Allāh es uno de ellos, con el valor añadido de que sus protagonistas son mujeres de excelente posición y buena familia, precisamente aquellas de las que más se esperaba que llevasen una vida recluida en sus casas.

El cuadro descrito por el desconocido alfaquí andalusí muestra, a pesar de su concisión, un fragmento de la vida cotidiana de estas mujeres. Debido a su elevada posición social, van al baño acompañadas

17 Deduzco, por el contexto y el contenido de la respuesta, que debe de tratarse de él, aunque en el texto sólo se le llame "Abd al-Malik". En su Kitāb Adab al-nisä', 'A. Turkī (ed.), Beirut, 1992, Ibn Habīb se refiere en dos ocasiones (pp. 218 y 229) a otras costumbres de las mujeres de Medina como fuente de autoridad para sus opiniones.

18 Al-Burzulī, Ŷāmi 'masā’il al-aḥkām, III, 661.

${ }^{19}$ Las opiniones de Ibn Hazm a este respecto han sido estudiadas por C. Adang, "Women's Access to Public Space According to al-Muhallā bi-l-Āthār”, M. Marín y R. Deguilhem (eds.), Writing the Feminine: Women in Arab Sources, Londres, 2002, 73-94.

20 Aguilar, V. y Marín, M., "Las mujeres en el espacio urbano de al-Andalus", Casas y palacios de al-Andalus, J. Navarro Palazón (ed.), Barcelona, 1995, 39-44 y Valencia Rodríguez, R., "La mujer y el espacio público de las ciudades andalusíes", M. I. Calero Secall y R. Francia Somalo (eds.), Saber y vivir: mujer, antigüedad y medievo, Málaga, 1996, 115-125; en ambos trabajos se utilizan los tratados de hisba para documentar la presencia pública de las mujeres.

Al-Qanțara (AQ) XXIX 1, enero-junio 2008, pp. 209-219 ISSN 0211-3589 
de sirvientas y esclavas, que las atienden y cuidan de sus ropas y otros enseres necesarios para la estancia en el baño ${ }^{21}$. Como es sabido, sólo las mujeres de buena familia tenían derecho, reconocido por la jurisprudencia, a ser «servidas» (majdūma) ${ }^{22} \mathrm{y}$ a que sus maridos pagasen el salario de sus criadas, de manera que acudir al baño acompañadas por un séquito de servidoras dejaba bien claro cuál era su rango social. Podían apreciarse igualmente otros signos de distinción personal y familiar: el valor y la calidad de las ropas, joyas, afeites y cosméticos se hacían públicos entre las mujeres que acudían al baño, convirtiéndose en materia de comentario y competición. El riguroso moralista egipcio de origen magrebí, Ibn al-Hāâŷy, era consciente de ello cuando afirma, en el siglo VIII/XIV, que las galas con las que se adornan las mujeres para ir al baño despiertan envidia en quienes no las poseen y que, en su afán por conseguir cosas semejantes, causan disgustos a sus maridos ${ }^{23}$.

La mujer sevillana que decidió tender una trampa a su enemiga utilizó para ello a sus criadas, con cuya lealtad contaba de antemano. Son las criadas quienes cumplen sus órdenes de mezclar la ropa de su dueña con la de la otra mujer y son ellas las que «descubren» que los vestidos presuntamente robados están mezclados con los de la acusada. Pero antes de llegar a ese punto, el relato introduce otra figura de mujer: la encargada del baño, a la que se llama sāhibat al-ḥammām o hammāmìya.

En el tratado de hisba de Ibn 'Abdūn se recomienda que «el recaudador del baño» (mutaqabbil al-hammām) no atienda a las mujeres para evitar ocasiones de «libertinaje y fornicación» ${ }^{24}$. Pero ni Ibn 'Abdūn ni, hasta donde he podido comprobar, ninguna otra fuente andalusí mencionan a las «encargadas del baño», aunque su existencia era de suponer, como requisito indispensable para gestionar la presen-

${ }^{21}$ Según un modelo de contrato reproducido por al-Ŷazīrī, entraban en esta categoría pañuelos, toallas, arcilla para lavarse la cabeza y pasta depilatoria [al-manādil wa-ardiyat al-tâyfîf wa-l-țafl li-gasl al-ru'ūs wa-l-nüra; al-Ŷazīrī (m. 585/1189), al-Maqșad al-mahmūd fi taljịs al-'uqūd, A. Ferreras (ed.), Madrid, 1998, 208].

${ }_{22}$ Marín, M., Mujeres en al-Ándalus, Madrid, 2000, 262.

23 Ibn al-Hāŷŷ, al-Madjal, s.1., 1981, II, 172-173.

${ }^{24} \mathrm{Ibn}$ 'Abūūn, Risāla fĩ l-qaḍ̂a' wa-l-hishba, E. Lévi-Provençal (ed.), El Cairo, 1955, 49; trad. E. Lévi-Provençal y E. García Gómez, Sevilla a comienzos del siglo XII. El tratado de Ibn Abdun, Madrid, 1948, 151.

Al-Qanțara (AQ) XXIX 1, enero-junio 2008, pp. 209-219 ISSN 0211-3589 
cia de las mujeres en el interior de los baños públicos y garantizar el correcto desarrollo de su función ${ }^{25}$.

En ese contexto, la intervención de la hammāmīya sevillana se dirige claramente a contener las consecuencias del escándalo que ve avecinarse y que no podía sino perjudicar la reputación del establecimiento en el que trabajaba y la suya propia. Ante la afirmación de la acusadora («ella es la única que ha podido coger mis ropas»), la encargada del baño replica recurriendo a un argumento de base social: la acusada pertenece a una familia noble y respetada (min afädil al-nās) y por tanto, no puede esperarse de ella que haya cometido el acto que se le imputa. Pero, puesto que las ropas han desaparecido, la hammāmìya se ofrece a compensar a su dueña, que debía de ser una buena clienta. El papel de la encargada del baño, como puede observarse en esta breve escena, no se limitaba a asegurar el bienestar físico de las mujeres, sino que mediaba en los conflictos que podían surgir entre ellas ${ }^{26}$. En este caso no tuvo éxito por la decidida actuación de la acusadora, que persistió en sus alegaciones y consiguió que testimoniaran a su favor las mujeres que la acompañaban (y quizá, aunque el texto no lo exprese, otras que estuvieran en ese momento en el baño y que vieron la ocasión de congraciarse con ella).

El relato deja entonces el ámbito del baño público y se traslada al tribunal de Ibn Hawt Allāh, juez mayor de Sevilla. La extremada concisión con que se narran los hechos elimina todos los pasos del proceso judicial, ofreciendo únicamente su resultado: Ibn Ḥawṭ Allāh dio

25 En Egipto, según testimonio de Ibn al-Hāŷŷy (al-Madjal, II, 172) esta profesional recibía el nombre de ballāna (como "asistente de baños" traduce este término "Abd ar-Raziq, A., La femme au temps des mamlouks en Egypte, El Cairo, 1973). Ibn al-Hāŷŷ,, loc. cit., recomienda que la ballāna no entre a ver a las mujeres mientras están en el baño; el tunecino Ibn al-Munāșif (m. 620/1223) también encarece que las mujeres no muestren su desnudez unas a otras en el baño [Tanbīh al-hukkām, ed. parcial M. J. Viguera, "La censura de costumbres en el Tanbīh al-hukkām de Ibn al-Munāșif (1168-1223), Actas de las II Jornadas de Cultura Árabe e Islámica (Madrid, 1980), Madrid, 1985, 602].

${ }^{26}$ La descripción que hace E. Lévi-Provençal de las actividades de las mujeres andalusíes en los baños públicos (Histoire de l'Espagne musulmane, III. Le siècle du califat de Cordoue, París, 1953, 431) parece inspirarse en la realidad marroquí contemporánea del autor, que no cita ninguna fuente escrita para documentar sus afirmaciones. Casi literalmente las reproduce Arié, R., "Aperçus sur la femme dans l'Espagne musulmane", Árabes, judias y cristianas: mujeres en la Europa medieval, C. del Moral (ed.), Granada, 1993, 143. También las recoge el peculiar trabajo de Mata Mata, P., "Digresiones (y transgresiones) a propósito del baño femenino en al-Andalus", Electronical Journal of Oriental Studies, VIII (2004), 1-13.

Al-Qanțara (AQ) XXIX 1, enero-junio 2008, pp. 209-219 ISSN 0211-3589 
crédito a los falsos testimonios y condenó a la acusada a una pena de cárcel o de azotes.

Al emitir su sentencia, el qāḍi estaba tomando en cuenta que, según la doctrina legal islámica, el supuesto delito no era de robo (sari$q a)$, castigado con la amputación en tanto que perteneciente a la categoría de hudüd, sino de hurto, ya que los bienes robados no se encontraban bajo custodia (hirz), al hallarse en un lugar, como el baño, accesible al público ${ }^{27}$. Desde época temprana, la jurisprudencia mālikí había tenido en cuenta esta distinción, aunque no siempre se estuvo de acuerdo en la definición exacta de los lugares que podían ser considerados como hirzz ${ }^{28}$. Ibn Hawt Allāh, en todo caso, debía de opinar que los baños no pertenecían a esa categoría y, en consecuencia, condenó a la acusada a la pena de cárcel o de azotes ${ }^{29}$.

Pero al pronunciar esa sentencia, Ibn Hawt Allāh estaba cometiendo un grave error, si no jurídico, desde luego social. Una mujer del rango de la acusada, miembro de los grupos de élite sevillanos ( $a^{\prime} y \bar{a} n$ ) podía esperar ser tratada de otro modo: recibir una amonestación del juez y ser devuelta a continuación a su familia. Al menos esto era lo que recomendaba un jurista como el oriental al-Kāsānī (m. 587/1189) para los terratenientes y la élite militar, mientras que los descendientes del Profeta y los juristas sólo debían ser amonesta-

27 Heffening, W., "Sarika”, $E I^{2}$, IX, 62-3. Véase también Santillana, D., Istituzioni di diritto musulmano malichita, Roma, II, 1938, 452 y ss. y Schacht, J., An Introduction to Islamic Law, Oxford, 1964, 175. Arévalo, R., Derecho penal islámico. Escuela malekita, Tánger, 1939, 102, hace equivaler sariqa a "hurto", de forma, a mi parecer, errónea, ya que no tiene en cuenta la definición de "robo" y "hurto" en castellano (DRAE, s.v. "robo": "delito que se comete apoderándose con ánimo de lucro de una cosa mueble ajena, empleándose violencia o intimidación sobre las personas, o fuerza en las cosas"; s.v. "hurto": "delito consistente en tomar con ánimo de lucro cosas muebles ajenas contra la voluntad de su dueño, sin que concurran las circunstancias que caracterizan el delito de robo").

${ }^{28}$ Véase la respuesta de Aṣbag b. al-Faraŷ (m. 225/840) a una cuestión planteada por 'Abd al-Malik b. Habīb: el robo de una silla de montar que lleva una acémila en un campo donde está pastando no debe castigarse con hadd porque lo robado no estaba en un lugar custodiado; en otra cuestión parecida, hay divergencias entre los juristas, ya que lo robado estaba en una yugada, y unos dicen que ese lugar es hirz y otros que no [Arcas Campoy, M., "Actos delictivos y acción penal en la Wädiḥa de Ibn Habīb", Boletín de la Asociación Española de Orientalistas, XXXIV (1998), 139-146, esp. 144].

${ }_{29}$ En el período almorávide, los casos estudiados por D. Serrano muestran la aplicación de la pena de cárcel para el delito de hurto. Cf. Serrano, D., "Twelve Court Cases on the Application of Penal Law under the Almoravids", Dispensing Justice in Islam. Qadis and their Judgments, M. Kh. Masud, R. Peters y D. S. Powers (eds.), Leiden, 2006, 473-493, esp. 480 y 489.

Al-Qanțara (AQ) XXIX 1, enero-junio 2008, pp. 209-219 ISSN 0211-3589 
dos por el enviado de un juez y a las clases bajas (sifla) se reservaba la posibilidad de ser amonestados, llevados ante el juez, encarcelados y azotados ${ }^{30}$. En al-Ándalus no faltan tampoco testimonios, sobre todo pero no únicamente literarios, que van en la misma dirección, algunos de los cuales fueron reunidos por E. García Gómez ${ }^{31}$. En ese contexto, la actuación de Ibn Hawt Allāh pudo deberse a un exceso de celo, a la firme convicción de que la justicia debía aplicarse por igual en todas las capas sociales, o a una apresurada toma de decisión, sin calcular adecuadamente sus consecuencias. También en el mismo contexto ha de situarse la reacción del hermano de la víctima, que se alzó públicamente en la mezquita aljama de Sevilla para anunciar que llevaría el caso ante la autoridad del califa almohade.

La intervención del poder político almohade en la práctica judicial ha sido subrayada recientemente por E.-M. Benouis y M. Fierro ${ }^{32}$. No sólo 'Abd al-Mu'min (527-558/1133-1163) se reservó la capacidad de decidir sobre la aplicación de la pena de muerte, sino que al-Mansūr (580-595/1184-1198) ejerció él mismo como qāḍī. El aparato político almohade tendía a una centralización acusada en todas sus esferas, y la de la justicia no fue una excepción. Los casos jurídicos de mayor importancia se llevaban ante el califa, convertido así en una instancia superior a la de los jueces ${ }^{33}$, tal como ocurrió en el caso de Ibn Ḥawt Allāh.

Ha de recordarse aquí que el protagonista de toda esta historia distaba mucho de ser un personaje de escasa importancia. No sólo era, en el momento de los hechos, juez mayor de Sevilla, la capital de los almohades en al-Ándalus, sino que, como ya se ha hecho notar, había sido preceptor de los hijos del califa al-Mansūr —entre ellos, el califa reinante en el momento de todo este asunto, al-Nāṣir (595-610/ 1199-1213) —. Los biógrafos de Ibn Ḥawt Allāh resaltan que esa fun-

${ }^{30}$ Citado por Schneider, I., "Imprisonment in Pre-Classical and Classical Islamic Law", Islamic Law and Society, 2 (1995), 157-173, esp. 163-64.

31 "Sobre la diferencia en el castigo de plebeyos y nobles", Al-Andalus, XXXVI (1971), 71-79.

32 Benouis, E.-M., "L'organisation du qaḍa' sous les almohades", Los almohades: problemas y perspectivas, P. Cressier, M. Fierro y L. Molina (eds.), Madrid, 2005, II, 505-524; Fierro, M., "The legal policies of the Almohad. Caliphs and Ibn Rushd's Bidāyat al-mujtahid", Journal of Islamic Studies, 10 (1999), 226-48 y "Doctrina y práctica jurídicas bajo los almohades", Los almohades: problemas y perspectivas, P. Cressier, M. Fierro y L. Molina (eds.), Madrid, 2005, II, 895-935.

33 Benouis, E.-M., "L'organisation du qadā" sous les almohades", 518.

Al-Qanțara (AQ) XXIX 1, enero-junio 2008, pp. 209-219 ISSN 0211-3589 
ción - junto con sus cualidades personales y su enorme saber- estuvo en el origen de su carrera como alto funcionario de la administración almohade, así como de su fortuna personal ${ }^{34}$. En palabras de uno de estos biógrafos, «los príncipes almohades lo tenían en mucha consideración, ya que había sido preceptor de al-Nāṣir y sus hermanos, a raíz de lo cual causó una excelente impresión en su padre, al-Manșūr, además de serle conocido por su ciencia, religiosidad y virtud» ${ }^{35}$.

En esta descripción se reconoce, a grandes rasgos, el perfil de los miembros de las élites locales andalusíes que se integraron sin dificultad en el entramado del poder almohade, incorporándose a las nuevas élites rectoras del Occidente islámico ${ }^{36}$. Es por tanto posible que Ibn Hawt Allāh confiase en que su posición y su cercanía al califa reinante, que había sido su discípulo en Marrakech, le permitiesen salir con bien del asunto. Sin embargo, una vez en al-Mahdìya, las cosas tomaron un cariz muy diferente. Parece deducirse del texto que la reclamación del demandante sevillano tuvo un cierto eco entre los alfaquíes locales, que debieron de discutir sus posibles implicaciones. En cualquier caso, el califa se inclinó por aceptar la demanda, concediendo a la mujer condenada por Ibn Hawt Allāh el derecho al talión.

No se sabe cuáles fueron los argumentos esgrimidos en la reclamación, pero sí que la injustamente acusada había otorgado a su hermano un poder para que la representase y exigiese, en su nombre, la concesión de ese derecho. De esto cabe inferir que la pena a la que había sido condenada en Sevilla, y sobre la cual tenía dudas el autor del relato, habría sido la de azotes, puesto que el talión se aplica en casos de muerte o de heridas que no son causa de muerte (qișās fi l-nafs, qișās fi-mā dün al-nafs) ${ }^{37}$.

Llevados quizá por la solidaridad de grupo, al ver a uno de los suyos en situación tan peligrosa, los alfaquíes de al-Mahdīya intercedieron ante el demandante para que, finalmente, aceptara renunciar a la aplicación de la pena. Ibn Hawt Allāh pudo entonces volver a

${ }^{34}$ Ibn al-Abbār, Al-Takmila, F. Codera (ed.), Madrid, 1887-89, II, 508.

35 Ibn al-Zubayr, Șilat al-șila (al-qism al-țāliț), 'A. S. al-Harrās y S. Arāb (eds.), al-Muhammadīya, 1993, 136.

36 Viguera Molíns, M. J., "Las reacciones de los andalusíes ante los almohades", Los almohades: problemas y perspectivas, P. Cressier, M. Fierro y L. Molina (eds.), Madrid, 2005, II, 705-735.

37 Schacht, J., "Kissāṣ", $E I^{2}$, V, 177-180. V. también Abou El Fadl, Kh., "Retaliation", Encyclopaedia of the Qur'an, IV, Leiden, 2004, 436-437.

Al-Qanțara (AQ) XXIX 1, enero-junio 2008, pp. 209-219 ISSN 0211-3589 
al-Ándalus, donde este episodio no se reflejó en su carrera como juez, cargo que volvió a ejercer hasta su muerte.

No es extraño que este relato no se haya incorporado a las biografías conservadas de Ibn Hawt Allāh. Sobre todo, porque el juez y tradicionista no sale de él muy bien parado; dictó una sentencia basada en falsos testimonios ${ }^{38}$, ofendió con ello a una poderosa familia sevillana y tuvo que sufrir la ignominia de ser condenado por el califa a la misma pena, librándose de ella sólo por la intervención de sus colegas en su favor. Nada, desde luego, que contribuyese a aumentar la reputación de juez ecuánime y lleno de virtudes que le conceden sus biógrafos.

Por otra parte, la extremada concisión del texto impide conocer muchas de las circunstancias en que se desarrolló todo el asunto, traído a colación en la obra de al-Burzulī a propósito de la intervención de los almohades en materias legales y jurídicas. Es muy posible, por tanto, que la intención del recopilador haya sido, al incluir este relato en su obra, la de mostrar las «pruebas» a las que podía someterse a los sabios por parte del poder almohade ${ }^{39}$. De paso, y aunque de forma a veces difícil de comprender, nos ha dejado un texto que permite atisbar comportamientos individuales y sociales en la Sevilla de comienzos del siglo VII/XIII. Las dos mujeres que comparten el protagonismo del relato con Ibn Ḥawt Allāh son buena prueba de ello, como lo es su inserción en redes familiares que compiten entre sí, pero que también las protegen y salen en su defensa cuando, como sucede con la falsamente acusada, se las injuria públicamente. La acción del hermano de esta mujer, emplazando al juez en la mezquita mayor de Sevilla, debe entenderse como el ineludible deber de restaurar el honor familiar y la alteración del orden social que suponía la condena de una mujer de rango al mismo castigo que hubiera merecido una delincuente común.

Recibido: 30/10/06

Aceptado: 07/06/07

38 Testimonios que, por otra parte, habían sido dados únicamente por mujeres, lo que en todo caso disminuía su valor probatorio.

${ }^{39} \mathrm{Cf}$. Benouis, E.-M., "Les savants mis à l'épreuve à l'époque almohade", M. L. Ávila y M. Fierro (eds.), Biografías almohades, II (EOBA, X), Madrid-Granada, 2000, 315-357. Por otra parte, ha de hacerse notar que el caso de Ibn Hawt Allāh se presenta también en la obra de al-Burzulī como un ejemplo de la escasa capacidad de los tradicionistas para ejercer como jueces.

Al-Qanțara (AQ) XXIX 1, enero-junio 2008, pp. 209-219 ISSN 0211-3589 